\title{
Subjective frequency norms for 330 Spanish simple and compound words
}

\author{
Alain Desrochers and Juana M. Liceras \\ University of Ottawa, Ottawa, Ontario, Canada \\ RAQuel FERnÁndez-FuerTes \\ University of Valladolid, Valladolid, Spain \\ AND \\ GLENN L. ThOMPSON \\ University of Ottawa, Ottawa, Ontario, Canada
}

\begin{abstract}
Ratings were collected from 102 native speakers of Spanish on the subjective frequency of occurrence of 330 Spanish words, including 120 deverbal compounds and their constituents. These ratings were found to be highly reliable, whether items were analyzed together or separately by type (i.e., compounds, nouns, verbs), as evidenced by indexes of internal consistency and test-retest reliability that were equal to or greater than .98 . The validity of the normative ratings was attested to by statistically significant correlations with objective frequency, estimated at .63 for all items together, and $.41, .51$, and .78 for compounds, nouns, and verbs, respectively. Among the substantive issues addressed was the potential dependency in ratings for compounds and their associated verb-noun constituents. No relationship was discerned, supporting the idea that compound and constituent ratings are statistically independent in this experimental task. The theoretical and methodological implications of the findings are discussed. The ratings can be downloaded from http://brm.psychonomic-journals.org/content/supplemental.
\end{abstract}

Two common word-formation procedures in modern alphabetical languages are derivation and compounding. A word is said to be derived by affixation when an affix (e.g., a prefix or a suffix) is added to a root word (e.g., read + er $\rightarrow$ reader $)$ or when an affix is substituted for another (e.g., reader $\rightarrow$ reading). A word is said to be derived by compounding when two lexemes (rarely more) are joined (e.g., flycatcher). Thus, compound words arise from the concatenation of distinct lexemes, which have their own frequency of occurrence in print and/or speech. In the study of lexical processing, this feature of compound words raises several theoretically important issues. For instance, if the lexicalization of compound words is complete, all properties of their constituents (e.g., their frequency of occurrence) may be opaque to language users and have no bearing on the perception of the whole words (for a discussion, see Chialant \& Caramazza, 1995; McQueen \& Cutler, 1998). The two primary aims of the present study are to establish subjective frequency norms for an extended set of Spanish words and address open questions, such as whether subjective evaluations of compounds and their constituents are interdependent.

\section{Estimating Lexical Frequency}

The two most commonly used sources for lexical frequency information are drawn from (1) the summed fre- quency of occurrence of individual word forms within a corpus of text (or transcribed speech) and (2) the subjective ratings of lexical frequency provided by a sample of respondents. The former is referred to as objective frequency and typically reflects the frequency with which professional writers (e.g., novelists, newspaper reporters) use these words. The latter is referred to as subjective frequency and reflects the experiences of a sample of participants asked to estimate word frequency by using a Likert-like scale, usually of 7 points, anchored by labels (e.g., $1=$ very infrequent; $7=$ very frequent). Texts, in the case of objective frequency, and participants, in the case of subjective frequency, may be sampled from a specific target population, depending on the interests of the researchers (e.g., movie transcripts, university students).

It has been argued that both objective and subjective frequency norms should be used jointly in the selection of lexical stimuli, regardless of whether word frequency is being experimentally controlled or manipulated (Gernsbacher, 1984; Thompson \& Desrochers, 2009; for examples of applications, see Bertram \& Hyönä, 2003; Monsell, Doyle, \& Haggard, 1989). One factor limiting the adoption of this recommendation is the relative imbalance of availability for these two types of norms. For instance, sources of objective frequency are now available in many alphabetic languages (for English, see, e.g., Baayen, Piepenbrock, \& Gulikers,

A. Desrochers, alain.desrochers@uottawa.ca 
1995; Zeno, Ivenz, Millard, \& Duvvuri, 1995; for Dutch, see, e.g., Baayen et al., 1995; for French, see, e.g., Lété, Sprenger-Charolles, \& Colé, 2004; New, Pallier, Brysbaert, \& Ferrand, 2004; for German, see, e.g., Baayen et al., 1995; for Greek, see, e.g., Ktori, van Heuven, \& Pitchford, 2008; for Portuguese, see, e.g., Marques, Fonseca, Morais, \& Pinto, 2007; for Spanish, see, e.g., Alameda \& Cuetos, 1995; Sebastián-Gallés, Martí, Cuetos, \& Carreiras, 2000). In comparison, the range of alphabetic languages for which subjective frequencies are available is limited (for English, see, e.g., Balota, Pilotti, \& Cortese, 2001; Carroll, 1971; Shapiro, 1969; Tryk, 1968; for French, see, e.g., Bonin et al., 2003; Desrochers \& Bergeron, 2000; Desrochers \& Thompson, 2009; Ferrand et al., 2008; Flieller \& Tournois, 1994; Forget, 2005; Gonthier, Desrochers, Thompson, \& Landry, 2009), as is the pool of words for which subjective frequency estimates are available in these languages. This imbalance may be attributed, in part, to the cost of collecting such ratings.

Objective frequency is often taken to be an indicator of the occurrence of words in the lexical environment, whereas subjective frequency reflects the impression left by these occurrences on the speaker or reader. As expected, these two estimates of word frequency are significantly and strongly correlated, but their association is far from perfect. Table 1 reports correlation coefficients drawn from studies carried out with different samples of native speakers of English or French $(r>.46)$. Note that similar correlation coefficients are obtained between objective frequency and subjective ratings of word familiarity $(r>.55$; Benjafield \& Muckenheim, 1989; Bird, Franklin, \& Howard, 2001; Stadthagen-Gonzalez \& Davis, 2006). This pattern is not surprising since standard instructions for rating familiarity explicitly refer to word frequency as a decision criterion (Toglia \& Battig, 1978), and the anchor labels used at each end of the rating scale may explicitly designate frequency of occurrence-for example, 1 (never seen before) and 7 (seen nearly every day) - (Stadthagen-Gonzalez \& Davis, 2006). Subjective frequency and familiarity ratings may therefore be tapping the same latent construct. However, it has been argued that subjective frequency is preferable as an operational definition because it is seemingly less confounded than familiarity with semantic variables (Balota et al., 2001).

Several factors may account for the less than perfect correlation between objective and subjective frequency estimates over and above measurement or sampling error (see Baayen, 2001; Thompson \& Desrochers, 2009). For instance, a common limitation of objective frequency estimates is that the probability of encountering certain itemsusually those of low frequency - is constrained by context (e.g., topics, media). These words are characterized as underdispersed in quantitative lexicography. Underdispersion entails, among other things, marked instability in objective frequency estimates across studies. If underdispersed words happen to be particular to a writing style or thematic domain that falls outside the population used to assemble the corpus, their estimated objective frequency will be biased downward. Conversely, underdispersed words that fall within the sampled population will see their estimated objective frequency systematically overestimated. There is reason to question the reliability or validity of objective frequency estimates for some words, and the validity of subjective frequency estimates has also been challenged. Balota et al. (2001), for instance, reported results that suggested that subjective estimation of word frequency is codetermined by word characteristics other than the frequency with which words are encountered, such as meaningfulness and the familiarity of orthographic or phonological patterns (see also Baayen, Feldman, \& Schreuder, 2006; Gonthier et al., 2009; Thompson \& Desrochers, 2009). One way of identifying items with dubious validity may then be to obtain both objective and subjective frequency estimates for as large a number of words as possible and to cross-validate them against each other.

\section{Word Frequency As a Determinant of Lexical Processing}

The importance of accurately estimating lexical frequency cannot be overstated. Of all the lexical charac-

Table 1

Correlations Between Objective $\left(\log _{10}\right)$ and Subjective Frequency Estimates Drawn From Different Studies in Two Alphabetic Languages

\begin{tabular}{|c|c|c|c|}
\hline Study & Source of Objective Frequencies & Word Sample Size & Pearson's $r$ \\
\hline \multicolumn{4}{|c|}{ English } \\
\hline Balota et al. (2001) & CELEX & 480 & .81 \\
\hline Tryk (1968) & Thorndike \& Lorge (1944) & 100 & .76 \\
\hline Carroll (1971) & Kučera \& Francis (1967) & 60 & .93 \\
\hline Shapiro (1969) & Kučera \& Francis (1967) & 60 & .92 \\
\hline \multicolumn{4}{|c|}{ French } \\
\hline Desrochers \& Thompson (2009) & New et al. (2004) & 3,505 & .67 \\
\hline Desrochers \& Bergeron (2000) & Imbs (1971) & 1,916 & .66 \\
\hline Gonthier et al. (2009) & New et al. (2004) & 1,612 & .71 \\
\hline Ferrand et al. (2008) & New \& Pallier (2005); New et al. (2004) & 1,493 & .81 \\
\hline Flieller \& Tournois (1994) & Imbs $(1971)$ & 998 & .76 \\
\hline Bonin et al. (2003) & New et al. (2001) & 866 & .46 \\
\hline Forget (2005) & New et al. (2004) & 565 & .67 \\
\hline Denis (1975) & Imbs (1971) & 100 & .61 \\
\hline
\end{tabular}

Note-All correlation coefficients are statistically significant $(p<.001)$. 
teristics known to influence visual word recognition, frequency of occurrence is clearly among the most potent: The accuracy and speed of responses to printed words are directly and positively related to their frequency of use in tasks that involve isolated words (e.g., lexical decision, single-word reading, word categorization; for reviews, see Monsell, 1991; Norris, 2006) and sentences (for a review, see Rayner, 1998). This lexical characteristic can also moderate the effect of other variables, such as orthographic regularity (Lupker, Brown, \& Colombo, 1997) and imageability (de Groot, 1989; James, 1975). Because of its ubiquitous influence on lexical processing, word frequency needs to be rigorously controlled when it is not intentionally manipulated in psycholinguistic experiments (i.e., in the case of a quasi-experiment evaluating a "between-words" variable).

As noted above, in the implementation of this sort of experimental control, compound words raise a special problem: The compound and its constituents are words, each with its own distinct frequency of occurrence in print. This feature has been exploited in experiments designed to investigate the possibility that compound words are decomposed into their constituents as they are processed. Such a view would be supported if constituent frequency was found to account for a significant amount of variance in reading tasks over and above the frequency of the compound itself. So far, most of these experiments have been carried out with speakers of Basque, Dutch, English, Finnish, German, or Spanish. These studies vary considerably in their choice of experimental tasks, design, item selection criteria, and dependent measures. It is perhaps unsurprising then that the results obtained in such experiments vary widely.

Some lexical decision studies of lexicalized concatenated compound words have failed to detect any significant constituent frequency effect (e.g., de Jong, Feldman, Schreuder, Pastizzo, \& Baayen, 2002; van Jaarsveld \& Rattink, 1988). Using the same methodology, other studies have reported a significant constituent frequency effect for the first lexeme only (Taft \& Forster, 1976), for the second lexeme only (Duñabeitia, Perea, \& Carreiras, 2007; Juhasz, Starr, Inhoff, \& Placke, 2003), or for both lexemes (Andrews, 1986; Inhoff, Starr, Solomon, \& Placke, 2008; Zwitserlood, 1994). ${ }^{1}$ These studies suggest that the pattern of frequency effects in compound word processing could depend on the way compound words are constructed in different languages, task requirements, the dependent variables being measured, and/or the interactions among these factors.

Of all the techniques currently available to researchers, the study of eye movements in the course of silently reading compound words embedded in sentences is particularly well suited to the investigation of word structure analysis. This experimental paradigm makes it possible to track the effect of item variables in the early stages of lexical processing through the analysis of first-fixation duration and, in later stages, through the analysis of subsequent fixations, regressive eye movements, and total fixation duration (see, e.g., Inhoff, Radach, \& Heller, 2000). When lexical processing is broken down into time-locked events, the conditions under which the characteristics of compound words or their constituents influence reading yield finer experimental observations. For instance, Pollatsek, Hyönä, and Bertram (2000) detected a significant frequency advantage (i.e., shorter fixation duration) for the first lexeme only on the first fixation; frequency effects for the compound words and all constituent lexemes were observed when total gaze duration (i.e., the sum of all fixation durations on a word prior to moving to another word) was examined (for similar results, see Andrews, Miller, \& Rayner, 2004). Follow-up studies have found that the magnitude of the constituent frequency effect was larger for the lexeme that contributes most to the meaning of the whole compound word (i.e., dominant vs. nondominant constituent; Inhoff et al., 2008). It may indeed be more efficient to process constituent lexemes, which are often more familiar than the full form, as the meaning of the compound word is accessed. In any case, the frequency of compounds, as well as of their constituents, may play a role in reading under certain conditions. It is therefore essential to estimate this lexical characteristic accurately.

As argued earlier, collecting subjective frequency ratings is an important part of ensuring that lexical frequency is accurately estimated. In the special case of compounds, multiple subjective frequency ratings are required: those of whole words, as well as those of their constituents. Such norms are valuable in and of themselves because they support the efforts of researchers in effecting statistical control or experimental control via matched lists and careful item selection. In addition, as with other experimental tasks (e.g., lexical decision, reading aloud or silent reading with eye tracking), subjective frequency judgment can be used to directly investigate the relationship between compound and constituent frequency. The results of such an investigation would speak at once to both the validity of the subjective frequency norms (e.g., is the estimation of compound frequency biased by constituent frequency?) and the same kind of substantive issue that is addressed by the studies reviewed above (i.e., are compounds processed independently of their constituent lexemes?).

\section{Purpose}

Accordingly, the purpose of the present study is twofold. First, it is intended as a contribution to the development of an extended Spanish lexical database for psycholinguistic research. To this end, we provide reliable subjective frequency ratings for a sizable set of compound-constituent pairs for research applications. Second, the study was designed to address a theoretically important issue that pertains directly to the validity of the reported normsnamely, the potential cross-contamination posed by the influence of constituent frequency on the estimation of compound frequency and vice versa.

\section{METHOD}

\section{Participants}

The sample comprised 102 Spanish-speaking volunteers (61 female) who were students in the Faculties of Arts, Science, and Engineering at the University of Valladolid. Their mean age was 
23.78 years $(S D=3.9)$, with a distribution ranging from 19 to 43 years. All participants were native speakers of Spanish, were free of a history of reading problems, and had normal or corrected-tonormal vision.

\section{Materials}

The lexical material included 124 deverbal compounds, ${ }^{2} 102$ nouns, and 104 verbs. The compound words (e.g., cazamoscas, "flycatcher") were sampled from dictionaries so as to represent a broad range of familiarity. The nouns and verbs included those found in the structure of the compound words (e.g., cazar, "to catch"; mosca, "fly"). Most deverbal compounds are in the Diccionario de la Lengua Española (Real Academia Española, 2001), and the others were gleaned from blogs and advertisements on the Internet. The validity of the latter sample of words was attested to by an independent group of 12 Spanish adults, who rated the compound words included in the study as genuine and assigned to them a consistent meaning (Liceras, Mongeon, Cuza, Senn, \& Spradlin, 2004).

The response booklet included two distinct parts. The first part included rating instructions and the 124 compound words mixed with 26 repeated items, for a total of 150 items. The second part included rating instructions and the 206 noun and verb items mixed with 24 repeated items, for a total of 230 items. These sets of items were presented separately in order to minimize the possibility of unintended priming of the compounds by their constituents. Within each set, the order of items was randomized. Each set was presented in two columns over five pages, with 15 items per column for compounds and 23 items per column for nouns and verbs. Each page was typed double spaced, and each item was accompanied by a space between parentheses to provide the frequency rating. The 7-point rating scale was presented horizontally at the top of each page of items. The label "poco frecuente" (very infrequent) appeared to the left of value 1 of the scale, and the label "muy frecuente" (very frequent) appeared to the right of value 7. The last page of the booklet was included to collect demographic data from the participants (e.g., age, gender, mother tongue, university program).

\section{Procedure}

Participants were tested in small groups of 5 to 10 people in a quiet classroom at the University of Valladolid and given as much time as they required to rate all items. At the beginning of each session, the purpose of the study was explained and instructions were provided. These instructions pointed out that some words occur more or less frequently in use. They provided explanations on the organization of the questionnaire and on the utilization of the 7-point scale. Participants were asked to examine the items and identify those to which they would give a rating of 1 or a rating of 7 before they started rating all items. They were asked explicitly to make use of the entire range of the scale. The verbatim instructions were adapted into Spanish from those used by Denis (1975).

\section{RESULTS}

The results are reported in the following order: First, we describe the screening procedure that was used to identify potential outliers among the participants. Second, the distributional properties of the subjective frequency norms are presented. Third, the internal consistency of the ratings is estimated using Cronbach's alpha and Guttman split-half correlation coefficients. Fourth, these tests are followed by an examination of the test-retest reliability for the subset of repeated items in the list. Fifth, the validity of the norms is assessed via correlations with available objective frequency and familiarity norms. Finally, substantive issues regarding the relationship between compound words and their verbal and noun constituents are investigated.

\section{Participant Screening}

In a normative study, the roles of items and participants are reversed so that the words are assigned a trait score that is based on their performance with the sample of participants. It is, therefore, possible to compute correlations between each participant's ratings and the mean ratings of the entire group. Low or negative correlations might indicate that the participants misunderstood the instructions (e.g., reversed the rating scale) or might belong to a different population of respondents. When all items in the study were considered together, the "participant-group" correlations observed with the present sample ranged from .60 to .91 , with one exceptional case producing a value of $.42(M=.80, S D=.08)$. Thus, all participants exceeded the .40 item-total correlation cutoff that is typically employed as a decision rule in the item-screening procedures of assessment-tool developers.

\section{Distributional Characteristics}

Overall, the distribution of mean ratings reported in this article was characterized by an average score of 4.69 , a standard deviation of 1.67 , a median of 5.23, and a range of 5.68 out of the possible 6 afforded by the 7-point scale, with a minimum value of 1.19 and a maximum value of 6.86. The skewness value of $-0.58(S E=0.13)$ and kurtosis value of $-1.05(S E=0.27)$ corresponded to standardized values of -4.92 and -4 , respectively, denoting significant negative skew and platykurtosis. Visual inspection of Figure 1 confirms a slightly $j$-shaped distribution, reflecting a larger representation of items at the high end of the frequency spectrum in the present sample.

\section{Internal Consistency}

Responses to the items used in this study $(N=330)$ were found to have a high degree of internal consistency. Both the Cronbach alpha and the Guttman lower-bound split-half coefficients were .99 . The same analysis was

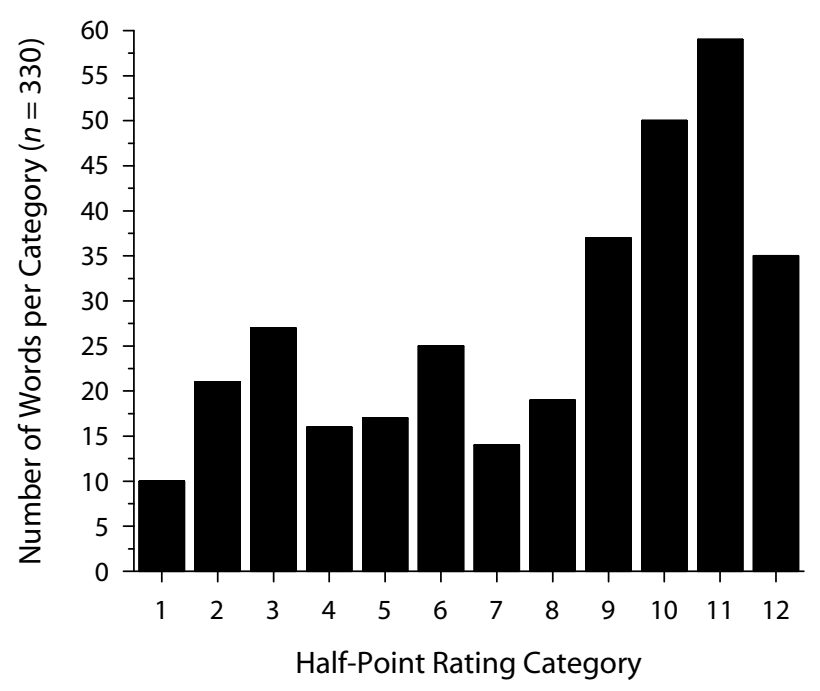

Figure 1. Distribution of subjective frequency ratings by halfpoints on the 7-point scale. 
performed separately for the compounds ( $n=124$, Cronbach and Guttman $=.99)$, nouns $(n=101$, Cronbach $=$ .98 , Guttman $=.99)$, and verbs $(n=105$, Cronbach and Guttman $=.99)$, yielding identical results. Therefore, the internal consistency of these ratings meets very high psychometric standards.

\section{Test-Retest Reliability}

The stability of the ratings across time was assessed using both items and participants as the units of analysis. The results of the by-items analysis are reported first, followed by the analyses conducted by subjects. All reported correlations are Pearson product-moment $r$, and all statistical tests were evaluated at the nominal .05 level of significance.

The by-items analysis indicated a strong test-retest correlation that approached unity $[r(50)=.99]$ when all words were included in the analysis. When the three classes of words were considered separately, the test-retest coefficients remained uniformly high: For compound words, $r(26)=.99$; for nouns, $r(12)=.98$; and for verbs, $r(12)=$ 99. Paired-samples $t$ tests failed to detect any practice effects whether all words $[t(49)=0.10, S E=0.02, p=.93]$ were considered simultaneously or whether compounds $[t(25)=0.86, S E=0.04, p=.40]$, nouns $[t(11)=-1.44$, $S E=0.04, p=.18]$, or verbs $[t(11)=-0.24, S E=0.04$, $p=.81]$ were considered individually.

A by-subjects analysis of the data, whereby correlations were performed separately for each participant, indicated that the average test-retest correlation was .88 $(S D=.09)$ when all items were included in the analysis. The average correlation dropped slightly to $.80(S D=.14)$ for compounds, to $.80(S D=.24)$ for nouns, and to $.86(S D=$ .15) for verbs considered separately. In accord with the by-items analysis, the by-subjects analysis of practice effects, conducted using the random coefficient methodology proposed by Lorch and Myers (1990), failed to detect any reliable change with repetition. This result remained consistent whether all items were considered together $[t(101)=0.10, S E=0.02, p=.49]$ or separately as compounds $[t(101)=1.00, S E=0.03, p=.49]$, nouns $[t(101)=-1.79, S E=0.03, p=.49]$, or verbs $[t(101)=$ $-0.26, S E=0.03, p=.49]$.

\section{Convergent Validity: Comparison With Objective Frequency and Familiarity}

To establish the validity of the ratings, the mean subjective frequency ratings were correlated with their log ob- jective frequency and mean subjective familiarity ratings, both of which were drawn from the Spanish lexical database LEXESP (Sebastián-Gallés et al., 2000). The present norms overlapped sufficiently with the LEXESP data to permit tests for the overall item sample, compounds only, nouns only, and verbs only. These correlation coefficients were positive and statistically significant ( all $p \mathrm{~s}<$ .001) (see Table 2). The magnitude of these relationships is within the typical range for correlations between subjective and objective frequency estimates (see Table 1), whether compounds or their constituents are considered. As noted in the introduction, rating instructions for the estimation of word familiarity often refer to lexical frequency as a decision criterion. Given this conceptual overlap, the strong correlation that was observed between subjective frequency and the familiarity ratings was not unexpected.

\section{Construct Validity: Compound Versus \\ Constituent Frequency}

The morphological relationships among the items used in the present study allow another substantive issue to be addressed - namely, the association between the frequency of a compound word and that of its constituent lexemes, which in this case comprise a verb and a noun. We investigated this relationship in two ways.

First, since compounds are expected to be constructed from relatively familiar components, the possibility of significant differences between the mean subjective frequency of compounds and that of their component words was examined. This verification was carried out with two paired-samples $t$ tests: one with nouns and the other with verbs. The result indicates that compounds $(M=3.81$, $S D=1.71)$ were indeed significantly lower in subjective frequency than either their constituent nouns $(M=6.08$, $S D=0.58)[t(121)=-14.17, S E=0.16, p<.001]$ or their constituent verbs $(M=5.69, S D=1.02)[t(123)=$ $-11.30, S E=0.17, p<.001]$. This result mirrors that observed with objective frequency, whereby compound words were found to be of lower $\log$ frequency $(M=1.20$, $S D=0.21)$ than either their nouns $(M=2.38, S D=0.64)$ $[t(50)=13.77, S E=0.09, p<.001]$ or their verbs $(M=$ $2.03, S D=0.47)[t(51)=12.04, S E=0.07, p<.001]$.

Second, the strength of the association between compounds and their component words was examined. The subjective frequency of the compounds was not found to be significantly correlated either with noun subjective frequency $[r(122)=.09, p=.35]$ or with verb frequency

Table 2

Correlation Between Subjective Frequency, Objective Frequency $\left(\log _{10}\right)$, and Familiarity Estimates in Spanish

\begin{tabular}{lcccc}
\hline \multicolumn{5}{c}{ and Familiarity Estimates in Spanish } \\
\cline { 2 - 5 } \multicolumn{1}{c}{ LEXESP Data } & Overall Sample & Compounds Only & Nouns Only & Verbs Only \\
\hline Objective frequency & $.65(248)$ & $.37(53)$ & $.53(102)$ & $.80(93)$ \\
Familiarity & $.75(143)$ & $.64(10)$ & $.76(92)$ & $.84(41)$ \\
\hline
\end{tabular}

Note-All correlation coefficients are statistically significant $(p<.001)$. The values in parentheses are the numbers of words available in the LEXESP database (Sebastián-Gallés et al., 2000) for computing these coefficients. 
$[r(124)=.15, p=.10]$. Thus, there is little direct evidence to suggest that the subjective frequency of compounds and their constituents are linearly related. A similar analysis with objective frequencies indicated that compound and noun frequency $[r(49)=.20, p=.17]$ and compound and verb frequency $[r(48)=.10, p=.51]$ were not significantly related. ${ }^{3}$ Taken together, these findings suggest that the subjective impression of frequency elicited by compounds is orthogonal to that of their components. The fact that participants were able to evoke independent frequency estimates for compounds and constituents (1) supports the validity of the norms, in that this is an accurate reflection of the pattern observed with objective frequency; and, more substantively, (2) is consistent with the idea that they have their own lexical representations.

Because of the importance of this issue both for the validity of the norms and for the substantive questions raised in the introduction, the relationships between compounds and their constituents were explored further. Specifically, the role of interactions was considered using the techniques for continuous $\times$ continuous variable interaction testing advocated by Cohen, Cohen, West, and Aiken (2003). The analysis was performed via a two-staged hierarchical regression procedure, whereby main or "direct" effects (i.e., noun frequency and verb frequency) are entered into the regression model first, and the interaction term (i.e., noun $\times$ verb frequency) is tested second. There were insufficient data points available, however, to perform the same analysis with objective frequency. The results of this hierarchical regression analysis, which predicted the subjective frequency of compounds from that of their constituent morphemes, are reported in Table 3.

The regression analysis confirms the absence of a direct relationship between constituent frequency and compound frequency, as evidenced by the fact that entering the two direct effects predicting compound frequency failed to improve the model significantly. Moreover, the addition of the interaction term in the second step did not offer any statistically significant improvement to the model. We considered the possibility that the hypothesized relationship might hold only for low-frequency compounds, but there was no trend in the data to support this idea. In sum, analyses based on this dataset offered no reliable evidence of either an additive or a nonadditive relationship between constituent frequency and compound frequency.

\section{DISCUSSION}

The task of cataloging the attributes of words in lexical databases is an ongoing project in many languages that serves the interests of researchers in a variety of domains, including psychology, linguistics, and education (for an overview, see Desrochers, Thompson, \& Fréchette, 2010). Much of the information needed in the development of such databases can be extracted from dictionaries (e.g., phonetic transcription, grammatical category, morphological structure, origin) or computed from the lexical entries (e.g., number of letters, phonemes, syllables, morphemes; bigram or biphone frequency; numbers of orthographic or phonological neighbors; see Davis \& Perea, 2005; Piñeiro \& Manzano, 2000; Sebastián-Gallés et al., 2000). However, other types of information (e.g., subjective frequency, familiarity, imageability, category typicality) require human judgment. The primary goal of the present study was to contribute to the development of an extended Spanish lexical database for psycholinguistic research by providing subjective frequency ratings for a theoretically interesting set of words.

The subjective frequency norms reported in this study were found to have a high level of accuracy, internal consistency, and test-retest reliability. By current standards, the psychometric properties of these norms are more than satisfactory. Consistent with previous research in other languages, subjective frequency estimates were found to be substantially but not perfectly correlated with estimates of objective frequency drawn from the most current source of relevant data (i.e., Sebastián-Gallés et al., 2000). When they are available for an extended set of words, both types of estimate can play a useful role in the selection of experimental items for research. It must be recognized, however, that each type of frequency estimate may be biased in its own way and that these biases do not necessarily cancel each other

Table 3

Regressions Predicting Subjective Compound Frequency From Subjective Estimates of Constituent Frequency

\begin{tabular}{|c|c|c|c|c|c|c|c|}
\hline Source & $F$ Change & $d f$ & $R^{2}$ Change & $b$ & $b S E$ & Zero-Order $r$ & Semipartial $r$ \\
\hline \multicolumn{8}{|c|}{ Step 1} \\
\hline $\begin{array}{l}\text { Subjective noun } \\
\text { frequency (A) }\end{array}$ & 1.86, n.s. & 2,119 & .03 & & & .09 & .10 \\
\hline $\begin{array}{l}\text { Subjective verb } \\
\text { frequency (B) }\end{array}$ & & & & & & .15 & .15 \\
\hline \multicolumn{8}{|c|}{ Step 2 (Final) } \\
\hline A & $<1$, n.s. & 1,118 & .004 & 27 & 27 & 09 & 09 \\
\hline B & & & & .30 & .17 & .15 & .16 \\
\hline $\mathrm{A} \times \mathrm{B}$ & & & & -.25 & .38 & $>-.01$ & -.06 \\
\hline \multicolumn{8}{|c|}{ Final Model } \\
\hline
\end{tabular}


out. Objective frequency estimates are largely dependent on text sampling procedures and sample size (see Baayen, 2001; Burgess \& Livesay, 1998); subjective frequency judgment may be influenced by other lexical attributes, such as imageability (see Thompson \& Desrochers, 2009). These considerations do not imply that the experimental or statistical control of frequency cannot be achieved with a high level of accuracy (especially if estimates are cross-validated using both objective and subjective frequency), but as Cutler (1981) once emphasized, caution is in order.

In the present study, a potential source of bias in subjective frequency ratings was investigated: the role of word constituents - in particular, their lexical frequency-in determining the subjective frequency estimates of Spanish deverbal compounds. Since these compounds are constructed from distinct lexemes with a frequency of use of their own, there was a priori a potential source of estimation bias that needed to be examined more closely. The potential bias failed to materialize, as the results reported here yielded no evidence of a direct or indirect influence of constituent frequency in the estimation of compound subjective frequency. The null findings suggest that, for this particular task, the processing of deverbal compounds is immune to the influence of constituent frequency. In the introduction, we reviewed evidence that the extent of this immunity may depend on compound construction procedures (see note 2), languages under consideration, experimental tasks, and dependent measures. The present results are only a part of the puzzle, a contribution to the growing body of empirical work cataloging the circumstances under which various frequency parameters are relevant to lexical processing.

Ultimately, the way compound words are processed may depend on what people do automatically when they read (i.e., the processes that are not under conscious control), as well as what they are reading for (i.e., the processes that are under conscious control). If we can assume that readers aim at activating lexical representations that best serve their immediate purpose, then future investigations could be directed to identifying the conditions under which the properties of constituent lexemes influence reading processes. A complete account of these dynamic processes will likely require multiple behavioral and physiological indicators. The set of norms reported here is intended to provide support for such empirical investigations.

\section{AUTHOR NOTE}

This research was funded by a grant from the Natural Sciences and Engineering Research Council of Canada to the first author. Thanks are due Esther Álvarez de la Fuente, Susana Muñiz Fernández, and K. Todd Spradlin for their assistance with data collection. We are grateful to Jose Ramón Alameda and an anonymous reviewer for their helpful comments on an earlier version of the article. Correspondence concerning this article should be addressed to A. Desrochers, School of Psychology, University of Ottawa, P.O. Box 450, Station A, Ottawa, ON, Canada K1N 6N5 (e-mail: alain.desrochers@uottawa.ca).

\section{REFERENCES}

Alameda, J. R., \& Cuetos, F. (1995). Diccionario de frecuencia de las unidades lingüisticas del castellano [Frequency dictionary of Spanish linguistic units]. Oviedo, Spain: Universidad de Oviedo.
ANDREws, S. (1986). Morphological influences on lexical access: Lexical or nonlexical effects? Journal of Memory \& Language, 25, 726740. doi:10.1016/0749-596X(86)90046-X

Andrews, S., Miller, B., \& RaYner, K. (2004). Eye movements and morphological segmentation of compound words: There is a mouse in mousetrap. European Journal of Cognitive Psychology, 16, 285-311. doi:10.1080/09541440340000123

BAAYEN, R. H. (2001). Word frequency distributions. Dordrecht: Kluwer.

BaAYen, R. H., Davidson, D. J., \& Bates, D. M. (2008). Mixed-effects modeling with crossed random effects for subjects and items. Journal of Memory \& Language, 59, 390-412. doi:10.1016/j.jml.2007 .12 .005

BaAyen, R. H., Feldman, L. B., \& Schreuder, R. (2006). Morphological influences on the recognition of monosyllabic monomorphemic words. Journal of Memory \& Language, 55, 290-313. doi:10.1016/ j.jml.2006.03.008

BaAyen, R. H., Piepenbrock, R., \& Gulikers, L. (1995). The CELEX lexical database (Release 2) [CD-ROM]. Philadelphia: University of Pennsylvania, Linguistic Data Consortium.

Balota, D. A., Pilotti, M., \& Cortese, M. J. (2001). Subjective frequency estimates for 2,938 monosyllabic words. Memory \& Cognition, 29, 639-647.

Benjafield, J., \& Muckenheim, R. (1989). Dates of entry and measures of imagery, concreteness, goodness, and familiarity for 1,046 words sampled from the Oxford English Dictionary. Behavior Research Methods, Instruments, \& Computers, 21, 31-52.

BERTRAM, R., \& HyöNÄ, J. (2003). The length of a complex word modifies the role of morphological structure: Evidence from eye movements when reading short and long Finnish compounds. Journal of Memory \& Language, 48, 615-634. doi:10.1016/S0749-596X(02)00539-9

Bird, H., Franklin, S., \& Howard, D. (2001). Age of acquisition and imageability ratings for a large set of words, including verbs and function words. Behavior Research Methods, Instruments, \& Computers, 33, 73-79.

Bonin, P., Méot, A., Aubert, L., Malardier, N., Niedenthal, P., \& CAPELle-ToczeK, M.-C. (2003). Normes de concrétude, de valeur d'imagerie, de fréquence subjective et de valence émotionnelle pour 866 mots [Concreteness, imageability, subjective frequency, and emotionality ratings for 866 words]. L'Année Psychologique, 103, 655694. doi: $10.3406 /$ psy.2003.29658

Burgess, C., \& Livesay, K. (1998). The effect of corpus size in predicting reaction time in a basic word recognition task: Moving on from Kučera and Francis. Behavior Research Methods, Instruments, \& Computers, 30, 272-277.

CARroll, J. B. (1971). Measurement properties of subjective magnitude estimates of word frequency. Journal of Verbal Learning \& Verbal Behavior, 10, 722-729. doi:10.1016/S0022-5371(71)80081-6

Chialant, D., \& Caramazza, A. (1995). Where is morphology and how is it processed? The case of written word recognition. In L. B. Feldman (Ed.), Morphological aspects of language processing (pp. 55-76). Hillsdale, NJ: Erlbaum.

Cohen, J., Cohen, P., West, S. G., \& Aiken, L. S. (2003). Applied multiple regression/correlation analysis for the behavioral sciences (3rd ed.). Mahwah, NJ: Erlbaum.

CUTLER, A. (1981). Making up materials is a confounded nuisance, or: Will we be able to run any psycholinguistic experiments at all in 1990? Cognition, 10, 65-70. doi:10.1016/0010-0277(81)90026-3

Davis, C. J., \& Perea, M. (2005). BuscaPalabras: A program for deriving orthographic and phonological neighborhood statistics and other psycholinguistic indices in Spanish. Behavior Research Methods, 37, 665-671.

DE Groot, A. M. B. (1989). Representational aspects of word imageability and word frequency as assessed through word association. Journal of Experimental Psychology: Learning, Memory, \& Cognition, 15, 824-845. doi:10.1037/0278-7393.15.5.824

de Jong, N. H., Feldman, L. B., Schreuder, R., Pastizzo, M., \& BAAYEN, R. H. (2002). The processing and representation of Dutch and English compounds: Peripheral morphological and central orthographic effects. Brain \& Language, 81, 555-567. doi:10.1006/ brln.2001.2547

DenIs, M. (1975). Représentation imagée et activité de mémorisation 
[Imagery representation and memory processes]. Paris: Centre National de la Recherche Scientifique.

Desrochers, A., \& Bergeron, M. (2000). Valeurs de fréquence subjective et d'imagerie pour un échantillon de 1,916 substantifs de la langue française [Subjective frequency and imageability ratings for a sample of 1,916 French nouns]. Revue Canadienne de Psychologie Expérimentale, 54, 274-325. doi:10.1037/h0087347

Desrochers, A., \& Thompson, G. L. (2009). Subjective frequency and imageability ratings for 3,600 French nouns. Behavior Research Methods, 41, 546-557. doi:10.3758/BRM.41.2.546

Desrochers, A., Thompson, G. L., \& Fréchette, S. (2010). The impact of information technology on the selection of lexical items for research in human experimental psychology. In A. M. Columbus (Ed.), Advances in psychology research (Vol. 62, pp. 215-234). Hauppauge, NY: Nova Science.

Duñabeitia, J. A., Perea, M., \& Carreiras, M. (2007). The role of the frequency of constituents in compound words: Evidence from Basque and Spanish. Psychonomic Bulletin \& Review, 14, 1171-1176.

Ferrand, L., Bonin, P., Méot, A., Augustinova, M., New, B., PalLier, C., \& Brysbaert, M. (2008). Age-of-acquisition and subjective frequency estimates for all generally known monosyllabic French words and their relation with other psycholinguistic variables. Behavior Research Methods, 40, 1049-1054. doi:10.3758/BRM.40.4.1049

Flieller, A., \& TourNoIs, J. (1994). Imagery value, subjective and objective frequency, date of entry into the language, and degree of polysemy in a sample of 998 French words. International Journal of Psychology, 29, 471-509. doi:10.1080/00207599408246553

ForgET, H. (2005). Valeurs d'imagerie et de fréquence subjective de 354 mots du vocabulaire sexuel de la langue française [Imageability and subjective frequency ratings for 354 words sampled from the sexuality vocabulary in the French language]. Revue Canadienne des Sciences $d u$ Comportement, 37, 49-69. doi: 10.1037/h0087245

GERNSBACHER, M. A. (1984). Resolving 20 years of inconsistent interactions between lexical familiarity and orthography, concreteness, and polysemy. Journal of Experimental Psychology: General, 113, 256281. doi:10.1037/0096-3445.113.2.256

Gonthier, I., Desrochers, A., Thompson, G., \& Landry, D. (2009). Normes d'imagerie et de fréquence subjective pour 1,760 mots monosyllabiques de la langue française [Imageability and subjective frequency ratings for 1,760 monosyllabic French words]. Revue Canadienne de Psychologie Expérimentale, 63, 139-149. doi:10.1037/ a0015386

ImBs, P. (1971). Études statistiques sur le vocabulaire français: Dictionnaire des fréquences I. Tables alphabétiques [Statistical studies on the French vocabulary: Frequency dictionary I. Alphabetic tables]. Paris: Didier.

INHOFF, A. W., RADACH, R., \& HELlER, D. (2000). Complex compounds in German: Interword spaces facilitate segmentation but hinder assignment of meaning. Journal of Memory \& Language, 42, 23-50. doi:10.1006/jmla.1999.2666

Inhoff, A. W., Starr, M. S., Solomon, M., \& Placke, L. (2008). Eye movements during the reading of compound words and the influence of lexeme meaning. Memory \& Cognition, 36, 675-687. doi:10.3758/ MC.36.3.675

JAMES, C. T. (1975). The role of semantic information in lexical decisions. Journal of Experimental Psychology: Human Perception \& Performance, 1, 130-136. doi:10.1037/0096-1523.1.2.130

Juhasz, B. J., Stark, M. S., Inhoff, A. W., \& Placke, L. (2003). The effects of morphology on the processing of compound words: Evidence from naming, lexical decisions and eye fixations. British Journal of Psychology, 94, 223-244. doi:10.1348/000712603321661903

Ktori, M., van Heuven, W. J. B., \& Pitchford, N. J. (2008). GreekLex: A lexical database of Modern Greek. Behavior Research Methods, 40, 773-783. doi:10.3758/BRM.40.3.773

KuČERA, H., \& FrANCIS, W. N. (1967). Computational analysis of presentday American English. Providence, RI: Brown University Press.

LÉTÉ, B., SPREnger-Charolles, L., \& Colé, P. (2004). MANULEX: A grade-level lexical database from French elementary school readers. Behavior Research Methods, Instruments, \& Computers, 36, 156-166.

Liceras, J. M., Mongeon, C., Cuza, A., Senn, C., \& Spradlin, K. T. (2004). La adquisición en el aula sin input formal: Los compuestos "exocéntricos" de las interlenguas del español. Revista Electrónica de Didáctica/Español Lengua Extranjera, 0, 1-28.
LORCH, R. F., JR., \& MYERS, J. L. (1990). Regression analyses of repeated measures data in cognitive research. Journal of Experimental Psychology: Learning, Memory, \& Cognition, 16, 149-157. doi:10.1037/0278 $-7393.16 .1 .149$

LupKer, S. J., Brown, P., \& Colombo, L. (1997). Strategic control in a naming task: Changing routes or changing deadlines? Journal of Experimental Psychology: Learning, Memory, \& Cognition, 23, 570590. doi:10.1037/0278-7393.23.3.570

Marques, J. F., Fonseca, F. L., Morais, A. S., \& Pinto, I. A. (2007). Estimated age of acquisition norms for 834 Portuguese nouns and their relation with other psycholinguistic variables. Behavior Research Methods, 39, 439-444.

McQueEn, J. M., \& CutLer, A. (1998). Morphology in word recognition. In A. Spencer \& A. M. Zwicky (Eds.), The handbook of morphology (pp. 406-427). Oxford: Blackwell.

MonselL, S. (1991). The nature and locus of word frequency effects in reading. In D. Besner \& G. W. Humphreys (Eds.), Basic processes in reading: Visual word recognition (pp. 148-198). Hillsdale, NJ: Erlbaum.

Monsell, S., Doyle, M. C., \& Haggard, P. N. (1989). Effects of frequency on visual word recognition tasks: Where are they? Journal of Experimental Psychology: General, 118, 43-71. doi:10.1037/0096 $-3445.118 .1 .43$

New, B., \& Pallier, C. (2005). Manuel de Lexique 3 [Lexique 3 users' manual]. Unpublished document, Université René-Descartes, Boulogne-Billancourt, Laboratoire de psychologie expérimentale.

New, B., Pallier, C., Brysbaert, M., \& Ferrand, L. (2004). Lexique 2: A new French lexical database. Behavior Research Methods, Instruments, \& Computers, 36, 516-524.

New, B., Pallier, C., Ferrand, L., \& Matos, R. (2001). Une base de données lexicales du français contemporain sur Internet: Lexique [A lexical database for contemporary French on the Internet: Lexique]. L'Année Psychologique, 101, 447-462.

NoRRIS, D. (2006). The Bayesian reader: Explaining word recognition as an optimal Bayesian decision process. Psychological Review, 113, 327-357. doi:10.1037/0033-295X.113.2.327

Piñeiro, A., \& Manzano, M. (2000). A lexical database for Spanishspeaking children. Behavior Research Methods, Instruments, \& Computers, 32, 616-628.

Pollatsek, A., Hyönä, J., \& Bertram, R. (2000). The role of morphological constituents in reading Finnish compound words. Journal of Experimental Psychology: Human Perception \& Performance, 26, 820-833. doi:10.1037/0096-1523.26.2.820

RAYNER, K. (1998). Eye movements in reading and information processing: 20 years of research. Psychological Bulletin, 124, 372-422. doi:10.1037/0033-2909.124.3.372

Real Academia Española (2001). Diccionario de la lengua española [Dictionary of the Spanish language] (22nd ed.). Madrid: EspasaCalpe.

Sebastián-Gallés, N., Martí, M. A., Cuetos, F. \& Carreiras, M. F. (2000). LEXESP: Léxico informatizado del español [LEXESP: A computerized word pool in Spanish]. Barcelona: Edicions de la Universitat de Barcelona.

Shapiro, B. J. (1969). The subjective estimation of relative word frequency. Journal of Verbal Learning \& Verbal Behavior, 8, 248-251. doi:10.1016/S0022-5371(69)80070-8

Stadthagen-GonZalez, H., \& Davis, C. J. (2006). The Bristol norms for age of acquisition, imageability, and familiarity. Behavior Research Methods, 38, 598-605.

TAFT, M., \& ForSTER, K. I. (1976). Lexical storage and retrieval of polymorphemic and polysyllabic words. Journal of Verbal Learning \& Verbal Behavior, 15, 607-620. doi:10.1016/0022-5371(76)90054-2

Thompson, G. L., \& Desrochers, A. (2009). Corroborating biased indicators: Global and local agreement among objective and subjective estimates of printed word frequency. Behavior Research Methods, 41, 452-471. doi:10.3758/BRM.41.2.452

THORNDIKE, E. L., \& LORGE, I. (1944). The teacher's word book of 30,000 words. New York: Columbia University, Teachers College Press.

Toglia, M. P., \& Battig, W. F. (1978). Handbook of semantic word norms. Hillsdale, NJ: Erlbaum.

TrYK, H. E. (1968). Subjective scaling of word frequency. American Journal of Psychology, 81, 170-177. doi:10.2307/1421261 
VAN JAARSVELD, H. J., \& RATTINK, G. E. (1988). Frequency effects in the processing of lexicalized and novel nominal compounds. Journal of Psycholinguistic Research, 17, 447-473. doi:10.1007/BF01067911

Zeno, S. M., Ivenz, S. H., Millard, R. T., \& Duvvuri, R. (1995). The educator's word frequency guide [Electronic data file]. Brewster, NY: Touchstone Applied Science.

ZWITSERLOOD, P. (1994). The role of semantic transparency in the processing and representation of Dutch compounds. Language \& Cognitive Processes, 9, 341-368. doi:10.1080/01690969408402123

\section{NOTES}

1. In the studies we reviewed, the constituent frequency effect for the first lexeme is typically robust in the analysis by subjects but marginal in the analysis by items. This pattern of results is often interpreted as being indicative of a failure to adequately capture between-items variability. It is also particularly ambiguous since the by-item test is typically the most robust to Type I error inflation due to aggregation bias (see Baayen, Davidson, \& Bates, 2008)

2. Spanish deverbal compounds are composed of a verb and a noun. The verb form corresponds to the third-person singular of the present in- dicative, and the noun form takes a generic $-s$ marker (e.g., abrebotellas, "bottle opener"; lavaplatos, "dishwasher"). The head-initial pattern of Spanish deverbals is also found in other alphabetic languages, such as French (e.g., ouvre-boites, "can opener"; gratte-ciel, "skyscraper"). By contrast, English deverbals are head-final (e.g., skyscraper, rather than *scrapesky). The verb typically takes an agentive -er suffix, and the noun takes the singular form.

3. The correlations among the objective frequencies of the compounds and their constituents are based on 48 and 49 words for verbs and nouns, respectively. Two words were found to be disproportionately influential in determining the estimated correlation according to a plot of Cook's distance values (see Cohen, Cohen, West, \& Aiken, 2003, p. 404) and were removed from this particular analysis.

\section{SUPPLEMENTAL MATERIALS}

The word norms discussed in this article may be downloaded from http://brm.psychonomic-journals.org/content/supplemental.

(Manuscript received March 8, 2009;

revision accepted for publication July 10, 2009.) 